\title{
Adversity Quotient, Anxiety, and Depression Symptoms of Medical Students
}

\author{
Ernesse Marie M. Berlin ${ }^{1}$ and Deborah Natalia E. Singson ${ }^{2}$ \\ ${ }^{1}$ Bermuon, Inc., Iloilo City, Philippines \\ 1,2 2University of Negros Occidental-Recoletos, Bacolod City, Philippines
}

\begin{tabular}{l} 
Article history \\
Submitted: 13 July 2020 \\
Revised: 5 November 2020 \\
Accepted: 13 November 2020 \\
\hline Keywords \\
Psychology \\
Adversity Quotient \\
Anxiety \\
Depression \\
Medical Students \\
Descriptive-Correlation \\
Iloilo City
\end{tabular}

\section{Article history}

mitted: 13 July 202

Accepted: 13 November 2020 and depression among students of a medical school in Iloilo City for the School Year 2018-2019. Three standardized instruments were used to gather data for this study: Adversity Quotient Profile, Zung Self-Rating Anxiety Scale, and the Beck Depression Index. A total of 94 students out of 104 participated in the study. The data were analyzed using Mean, Standard Deviation, and Pearson r.

Results. Female students were shown to have better scores than their male counterparts. Both older and younger students are found to have below-average levels of Adversity Quotient (AQ). In terms of living arrangements, only the group who still live with their relatives have shown to have below-average levels. In contrast, the group who live alone and the group who live with non-relatives have average AQ levels. The overall AQ level of the group is below average. Levels of anxiety among students were on normal levels. In terms of depression, both male and female students are shown to have mild levels of depression. Both age groups identified in this study are also going through mild levels of depression. When looking into living arrangements, the groups who live with relatives and non-relatives have mild levels of depression. In contrast, those who live on their own have normal levels of depression. When checked, anxiety and depression do not have a significant relationship with Adversity Quotient. This means that one's anxiety or depression does not affect one's Adversity Quotient.

Conclusion. Based on the findings of the study, Adversity Quotient (AQ) does not always rely on a person's level of anxiety or depression. Results showed that students have below-average levels of Adversity Quotient. The students also have normal levels of anxiety but mild levels of depression. The normal levels indicate that they are only reactionary and appropriate to whatever forms of stressor they are presented with. However, this study indicates that better mental health practices should be introduced to students.

Practical Value of the Paper. This study is significant due to its contribution to the literature on medical students' mental health. Studies on medical students, in general, are very few, and there is a need to provide the correct response or assistance in terms of mental health. A wellness program was designed based on the results gathered from this paper. The wellness program targets different areas to safeguard the mental health of the first year medical students. Further studies are recommended, and the program was revised to include medical students of higher years. 


\section{References}

Ediz, B., Ozcakir, A. \& Bilgel, N. (2016). Depression and anxiety among medical students: examining scores of the Beck Depression and Anxiety inventory with the depression anxiety and stress scale with student characteristics. Cogent Psychology, 4, 1. Doi: 10.1080/23311908.2017.1283829

Hope, V. \& Henderson, M. (2014). Medical student depression, anxiety, and distress outside North America: a systematic review. Medical Education, 48 (10): 963-79. doi: 10.1111/medu.12512

Houpy, J. C., Lee, W. W., Woodruff, J. N. \& Pincavage, A. T. (2017). Medical student resilience and stressful clinical events during clinical training. Medical Education Online, 22 (1). doi: 10.1080/10872981.2017.1320187

Kerebih, H., Ajaeb, M. \& Hailesilassie, H. (2017). Common mental health disorders among medical students in Jimma University, South West Ethiopia. African Health Sciences. 17(3): 844. Doi: 10.4314/ahs.v17i3.27

Puthran, R., Zhang, M. W., Tam, W. W., \& Ho, R. C. (2016). Prevalence of depression amongst medical students: A meta-analysis. Medical Education, 50(4), 456-468. doi:10.1111/medu.12962

Risal, A., Manandhar, K., Linde, M., Steiner, T., and Holen, A. (2016). Anxiety and depression in Nepal: prevalence, comorbidity, and associations. BMC Psychiatry, 16: 102. https://doi.org/10.1186/s12888-016-0810-0

Roh, M. S., Jeon, H. J., Kim, H., Han, S. K. \& Hahm, B. J. (2010). The prevalence and impact of depression among medical students: a nationwide cross-sectional study in South Korea. Academic Medicine, 85(8), 1384-90. doi: 10.1097/ACM.0b013e3181df5e43

Shi, M., Liu, L., Wang, Z. Y., \& Wang, L. (2016). Prevalence of depressive symptoms and its correlations with positive psychological variables among Chinese medical students: an exploratory cross-sectional study. BMC Psychiatry, 11 (16) 3. Doi: 10.1186/s12888-016-0710-3.

Souri, H. \& Hasanirad, T. (2011). Relationship between resilience, optimism, and psychological well-being in students of medicine. Procedia- Social and Behavioral Sciences, 30, 1541-1544. Doi: https://doi.org/10.1016/j. sbspro.2011.10.299

Thompson, G., Mcbride, R. B., Hosford, C. C., \& Halaas, G. (2016). Resilience Among Medical Students: The Role of Coping Style and Social Support. Teaching and Learning in Medicine,28(2), 174-182. doi:10.1080/10401334. 2016.1146611

\section{Correspondence:}

Ernesse Marie M. Berlin [earnestinberlin@gmail.com]

https://orcid.org/0000-0002-6286-8177 